NBER WORKING PAPER SERIES

\title{
REAL-TIME MACROECONOMIC MONITORING: REAL ACTIVITY, INFLATION, AND INTERACTIONS
}

\author{
S. Boragan Aruoba \\ Francis X. Diebold \\ Working Paper 15657 \\ http://www.nber.org/papers/w15657
NATIONAL BUREAU OF ECONOMIC RESEARCH
1050 Massachusetts Avenue
Cambridge, MA 02138
January 2010

For helpful comments we thank seminar and conference participants at the 2010 Annual Meeting of the American Economic Association, the Fifth Annual Workshop on Data Revision in Macroeconomic Forecasting and Policy (CIRANO, Montreal), the Federal Reserve Bank of Philadelphia, Black Rock, and the University of Pennsylvania. We are especially grateful to Dean Croushore, Loretta Mester, Jeremy Piger, Calvin Price, Glenn Rudebusch, Keith Sill, Tom Stark and Simon van Norden. For research support we thank the National Science Foundation and the Real-Time Data Research Center at the Federal Reserve Bank of Philadelphia. The views expressed herein are those of the authors and do not necessarily reflect the views of the National Bureau of Economic Research.

NBER working papers are circulated for discussion and comment purposes. They have not been peerreviewed or been subject to the review by the NBER Board of Directors that accompanies official NBER publications.

(C) 2010 by S. Boragan Aruoba and Francis X. Diebold. All rights reserved. Short sections of text, not to exceed two paragraphs, may be quoted without explicit permission provided that full credit, including (c) notice, is given to the source. 
Real-Time Macroeconomic Monitoring: Real Activity, Inflation, and Interactions

S. Boragan Aruoba and Francis X. Diebold

NBER Working Paper No. 15657

January 2010

JEL No. E3

\title{
ABSTRACT
}

We sketch a framework for monitoring macroeconomic activity in real-time and push it in new directions. In particular, we focus not only on real activity, which has received most attention to date, but also on inflation and its interaction with real activity. As for the recent recession, we find that (1) it likely ended around July 2009; (2) its most extreme aspects concern a real activity decline that was unusually long but less unusually deep, and an inflation decline that was unusually deep but brief; and (3) its real activity and inflation interactions were strongly positive, consistent with an adverse demand shock.

\author{
S. Boragan Aruoba \\ Department of Economics \\ University of Maryland \\ 3105 Tydings Hall \\ College Park, MD 20742-7211 \\ aruoba@econ.umd.edu \\ Francis X. Diebold \\ Department of Economics \\ University of Pennsylvania \\ 3718 Locust Walk \\ Philadelphia, PA 19104-6297 \\ and NBER \\ fdiebold@sas.upenn.edu
}




\section{Introduction}

Real economic agents, making real decisions in real time, need accurate and timely estimates of the state of macroeconomic activity. Every day, literally millions of economic agents (business people, retail and institutional investors, financial institutions, economists, households, ...) explicitly or implicitly attempt to form and update views on macroeconomic activity as new information arrives. Significant parts, for example, of the first few pages of any day's Wall Street Journal or Financial Times are typically devoted to recently-released or soon-to-be-released data and its likely implications for business conditions.

To help meet this demand, we have earlier supplied and illustrated a framework for high-frequency measurement of macroeconomic activity in a systematic, replicable, and statistically optimal manner in Aruoba et al. (2009). ${ }^{1}$ We are hardly alone in appreciating the desirability and benefits of high-frequency measurement, however, as interest in the area has escalated rapidly. Academic research on high-frequency (indeed real-time) macroeconomic measurement is now voluminous, with leading reference works featuring it prominently (e.g., Croushore (2006)), and recently-established annual conferences chronicling and promoting new developments. ${ }^{2}$ Even Google is now in the game, as industry and academics work together to expand the frontier; see Choi and Varian (2009).

Improved real-time macroeconomic measurement is of interest not only to private agents, but also to policy makers. Both groups seek to use better information to make better decisions. Hence central banks and NGOs worldwide have recently devoted significant resources to real-time macroeconomic monitoring, as for example with the Federal Reserve Bank of Philadelphia's Real-Time Data Research Center ${ }^{3}$, the Bank of Italy and CEPR's EuroCOIN project $^{4}$, and the Bank of Spain's Euro-STING project. ${ }^{5}$

Similarly, leading policy-oriented academic macroeconomists are focusing squarely on real-time challenges, grappling with policy formulation and evaluation in the face of evolving current information, as for example in John Taylor's inaugural Feldstein address to the NBER (Taylor (2009)).

\footnotetext{
${ }^{1}$ See also our more refined real-time implementation and additional materials maintained by the Federal Reserve Bank of Philadelphia at http://www.philadelphiafed.org/research-and-data/real-timecenter/business-conditions-index.

${ }^{2}$ See for example the ongoing series of "Real-Time Data Conferences" sponsored by CIRANO (Montreal), the most recent of which is the October 2009 Fifth Annual Workshop on Data Revision in Macroeconomic Forecasting and Policy.

${ }^{3}$ See http://www.philadelphiafed.org/research-and-data/real-time-center.

${ }^{4}$ See Altissimo et al. (2007), and for recent details see http://eurocoin.cepr.org.

${ }^{5}$ See Camacho and Perez-Quiros (2009).
} 
Against this background, in this paper we provide both retrospective and prospective assessment of progress in real-time macroeconomic monitoring. We focus not only on real macroeconomic activity, which has received most attention to date, but also on inflation and its interaction with real activity. In section 1 we present our basic dynamic factor framework, which we use throughout. In section 2 we use the framework to assess real activity (section 2.A), inflation (section 2.B), and their interaction (section 2.C). We conclude in section 3 .

\section{A Dynamic Factor Model for Economic Indicators}

Our concern is with accurate real-time assessment of current macroeconomic activity; that is, our concern is with "nowcasting," not forecasting. Accurate nowcasting promotes good decision making, and although far from simple, nowcasting can likely be done with greater success than longer-horizon forecasting. ${ }^{6}$ We work in a "small data" environment in the sense of Diebold (2003), with roughly a half-dozen indicators of economic activity. ${ }^{7}$ We prefer small data because it lets us devote the necessary care and attention to the selection and monitoring of indicators. In addition, recent work reveals that maximum-likelihood estimation in small-data frameworks has surprisingly good properties, even when the true data-generating process is "big-data". 8

We observe a variety of indicators, all of which contain information about the latent state of economic activity. Hence we work in a state space framework with multiple indicators and a single latent activity factor, which we extract optimally using the Kalman filter. We use mixed-frequency data, specifying the model at high frequency and allowing for a large amount of missing data (for the less-frequently observed variables).

Building directly on important earlier work of Stock and Watson (1989) and Mariano and Murasawa (2003), we postulate dynamic factor structure at high frequency. (With no loss of generality, call the highest frequency "daily".) The latent macroeconomic activity factor $x_{t}$ evolves daily with covariance-stationary autoregressive dynamics,

$$
x_{t}=\rho_{1} x_{t-1}+\ldots+\rho_{p} x_{t-p}+\eta_{t}
$$

where $\eta_{t}$ is a white noise innovation with unit variance. The $i$-th covariance-stationary daily

\footnotetext{
${ }^{6}$ In the jargon of business conditions indexes, we seek to produce coincident, not leading, indexes of economic activity. Coincident indexes are more fundamental, as a leading index is simply a forecast of a coincident index.

${ }^{7}$ The exact number of indicators depends on the application, as we describe subsequently.

${ }^{8}$ See Doz et al. (2006), Jungbacker and Koopman (2008), and Bai and Ng (2008).
} 
indicator $\hat{y}_{t}^{i}$ may depend linearly on $x_{t}$ and $q^{i}$ own-lags:

$$
\hat{y}_{t}^{i}=c^{i}+\beta^{i} x_{t}+\gamma_{1}^{i} \hat{y}_{t-D^{i}}^{i}+\gamma_{2}^{i} \hat{y}_{t-\left(2 D^{i}\right)}^{i}+\ldots+\gamma_{q^{i}}^{i} \hat{y}_{t-\left(q^{i} D^{i}\right)}^{i}+\varepsilon_{t}^{i}
$$

where $D^{i}$ is the number of days in the observational frequency of indicator $i$ (e.g., $D^{i}=7$ if $\hat{y}_{t}^{i}$ is observed weekly), and where the $\varepsilon_{t}^{i}$ are white noise shocks, uncorrelated with each other and with $\eta_{t}$.

Note that most indicators, although evolving daily, are not observed daily. If $y_{t}^{i}$ denotes $\hat{y}_{t}^{i}$ observed at a lower frequency, then the relationship between $y_{t}^{i}$ and $\hat{y}_{t}^{i}$ depends on whether $\hat{y}_{t}^{i}$ is a stock or flow variable. If $\hat{y}_{t}^{i}$ is a stock, then $y_{t}^{i}=\hat{y}_{t}^{i}$ when $y_{t}^{i}$ is observed, and $y_{t}^{i}$ is "missing" otherwise. Alternatively, if $\hat{y}_{t}^{i}$ is a flow, then $y_{t}^{i}=\sum_{j=0}^{D^{i}-1} \hat{y}_{t-j}^{i}$ when $y_{t}^{i}$ is observed, and $y_{t}^{i}$ is missing otherwise.

Our framework corresponds to a state space system: $y_{t}=Z \alpha_{t}+\Gamma w_{t}+\varepsilon_{t}, \alpha_{t+1}=T \alpha_{t}+R \eta_{t}$, $\varepsilon_{t} \sim(0, H), \eta_{t} \sim(0, Q), t=1, \ldots, \mathcal{T}$, where $y_{t}$ is a vector of observed variables, $\alpha_{t}$ is a vector of state variables, $w_{t}$ is a vector containing ones and lagged dependent variables, and $\mathcal{T}$ denotes sample size. In general, $y_{t}$ will contain many missing observations, reflecting not only missing daily data due to holidays, but also, and more importantly, the fact that most variables are observed less often than daily. In addition, several of the system parameter matrices may be time-varying, because of variation in $D^{i}$ across $t$ (e.g., different months contain different numbers of days). Note also that flow variables generally produce very highdimensional state vectors, because observed flow variables depend on $x_{t}$ and $\max _{i}\left\{D^{i}\right\}-1$ lags of $x_{t}$, which produces a state vector of dimension $\max \left\{\max _{i}\left\{D^{i}\right\}, p\right\}$, in contrast to the $p$-dimensional state associated with a system involving only stock variables.

Importantly for us, and despite the missing data and potentially time-varying system matrices, the standard Kalman filter and associated likelihood evaluation via predictionerror decomposition remain valid in our environment, subject to some simple modifications. This is well-known, as discussed for example in Durbin and Koopman (2001) and exploited in Aruoba et al. (2009) and Aruoba and Diebold (2009). In addition, the "Harvey cumulator" Harvey (1991) (pp. 313-318) eliminates the dimensionality problem by recognizing that the state space measurement equation requires only the sums of current and $D^{i}-1$ lags of $x_{t}$, not each of the summands separately. The upshot: We can use simple modifications of the standard Kalman filter and smoother to produce exact maximum-likelihood estimates of our model, and to produce optimal estimates of its latent macroeconomic activity factor, $x_{t}$. We now proceed to do so. 


\section{Monitoring Macroeconomic Activity}

We have described real activity monitoring in Aruoba et al. (2009), and we have provided enhancements in Aruoba and Diebold (2009). Indeed the so-called ADS Index is now maintained by the Federal Reserve Bank of Philadelphia, updated in real time and written to the web whenever new data, or revisions of existing data, are released. ${ }^{9}$ Here we push the ADS framework in new directions, focusing not only on real activity, but also on inflation and its interaction with real activity.

To maximize transparency, in this paper we use a monthly base frequency for both real activity and inflation analysis, eliminating many of the complications mentioned earlier (time-varying system matrices, high-dimensional state vectors, etc.) We use indicators seasonally adjusted by the relevant reporting agency. We transform all indicators to logarithmic changes; hence all are flows. We allow for $p=3$ autoregressive lags in the transition equation (1). We allow for $q^{i}=3 / D^{i}$ own autoregressive lags in the measurement equation (2); that is, we allow for one (quarterly) lag of quarterly variables, and we allow for three (monthly) lags of monthly variables.

\subsection{Real Activity}

We use five indicators, from the 11/23/2009 data vintage: payroll employment (monthly, from the Bureau of Labor Statistics (BLS), 1960.02-2009.10), industrial production (monthly, from the Federal Reserve Board (FRB), 1960.02-2009.10), real personal income less transfers (monthly, from the Bureau of Economic Analysis (BEA), 1960.02-2009.09), real manufacturing and trade sales (monthly, from BEA, 1967.02-2009.08), and real GDP (quarterly, from BEA, 1960.II-2009.III). Note in particular the different ending dates of the indicators in the $11 / 23 / 2009$ vintage, as is typical, due to differing release timeliness.

We plot the five indicators in the top panel of Figure 1 together with NBER "recession bars". ${ }^{10}$ It is clear that idiosyncratic noise in the individual indicators masks much of the real activity information contained in them. The extracted real activity factor, in contrast, is much less noisy, as seen in the middle panel of Figure 1. The estimation results (not shown to save space) reveal that all indicators load positively and significantly on the real activity factor in our estimated equation (2). Conversely, the extracted factor is driven by

\footnotetext{
${ }^{9}$ See http://www.philadelphiafed.org/research-and-data/real-time-center/business-conditions-index.

${ }^{10}$ As of the date of writing (January 2010), the NBER ending date for the recent recession remains undeclared. We end the last recession bar in July 2009, which is when our real activity factor returns to zero.
} 
all of the underlying indicators. In optimally extracting the state of real activity, however, the Kalman filter effectively eliminates much of the idiosyncratic noise by averaging both over the cross section and over time.

Several features of our real activity index are noteworthy, as highlighted in Figure 2, which contains real activity plots during 36-month windows containing the six most recent recessions. ${ }^{11}$ First, movements in our real activity factor cohere strongly with the NBER chronology, plunging during NBER recessions. Second, the roughly 1985-2007 "Great Moderation" in the volatility of real activity is clear, even if now relegated to the dustbin of history. Third, the recent recession, which is of special interest, begins in very late 2007, in accord with the NBER's dating, and it shows a clear trough in January 2009, after which it recovers steadily, with the recession ending (in our assessment) in July 2009. ${ }^{12}$ And finally, Figure 3 emphasizes that the recent recession, although quite deep, is most notably very long relative to its post-1960 competitors. ${ }^{13}$ The extreme duration severity interacts with the moderately extreme depth severity to produce the extreme overall severity revealed in the bottom panel of Figure $3 .^{14}$

\subsection{Inflation}

Our approach to measuring inflation parallels precisely our approach to measuring real activity. ${ }^{15}$ As with real activity indicators, we see many inflation indicators, each of which contains potentially valuable, but incomplete and noisy, information about the underlying common component. We include wages among our indicators because they are a crucially important price, and one not not explicitly contained in standard price indexes.

Our inclusion of wages has both theoretical and empirical nuances. On the theoretical side, inclusion of wages is motivated by modern dynamic stochastic general equilibrium models, which suggest that optimal monetary policy rules may be approximated by Taylor-

\footnotetext{
${ }^{11}$ Each 36-month window begins 12 months before the corresponding recession.

${ }^{12}$ The trough in September 2008 was caused by a set of exogenous events and should be discounted entirely. In particular, September industrial production was severely affected by a largely exogenous "triple shock" (Hurricanes Gustav and Ike, and a strike at a major aircraft manufacturer), which caused an annualized September 2008 drop of nearly fifty percent and a correspondingly huge October rebound. September/October manufacturing and trade sales behaved similarly.

${ }^{13}$ See Diebold and Rudebusch (1992) for discussion and analysis of recession durations.

${ }^{14}$ We define duration severity to be recession length in months, depth severity to be the largest (absolute) value of the real activity index during the recession, and overall severity to be the (absolute) sum of the real activity index values during the recession.

${ }^{15}$ Hence, for example, our focus is very different from the recent work of Reis and Watson (2009), who use only prices of consumption goods and use a dynamic factor model to decompose them in a way that helps make contact with modern theories of inflation dynamics.
} 
type rules that respond to price inflation and wage inflation (e.g., Schmitt-Grohe and Uribe (2007)) or even wage inflation exclusively (e.g., Levin et al. (2006)).

On the empirical side, inclusion of wages raises the issue of what wage indicator(s) to use. Wage indicators effectively fall into one of two camps, "hourly compensation" or "unit labor cost". We focus on hourly compensation, as unit labor costs confound wage-rate movements with productivity movements.

We use six inflation indicators from the 11/23/2009 data vintage: the all-items CPI (monthly, from BLS, 1960.01-2009.10), the finished-goods PPI (monthly, from BLS, 1960.012009.10), a non-energy commodity price index (monthly, Standard and Poor's GSCI NonEnergy Commodities Index, 1970.01-2009.10), a spot oil price (monthly, West Texas Intermediate, from FRB St. Louis FRED database, 1960.01-2009.10), the GDP deflator (quarterly, from BEA, 1960.I-2009.III), and hourly compensation in the non-farm business sector (quarterly, from BLS, 1960.I-2009.III).

We again use the Kalman filter to estimate a simple dynamic factor model and extract the latent state, resulting in an inflation index, which we show in the top panel of Figure 4. The estimation results (not shown to save space) reveal that all indicators load significantly on the factor in our estimated equation (2).

Several features of the top panel of Figure 4 deserve mention. First, the inflation of the 1970s is apparent, as is its retreat, which began with Paul Volcker's appointment as Chairman of the Federal Reserve Board in August 1979 and was accomplished by 1984. Second, not only inflation's level, but also its volatility, was low from then until the late 1990s. In contrast, inflation volatility shows a marked increase from the late 1990s onward, a phenomenon potentially linked to inflation's recent decreased forecastability, as documented by Stock and Watson (2007). Finally, the recent period 2007-2009 is especially important, so we zoom in on it in the bottom panel of Figure 4. The historically-unprecedented (at least since 1960) 2008 inflation drop was extremely sharp but also extremely brief. The entire episode ultimately lasted just six months.

\section{$3.3 \quad$ Interactions}

Prices and quantities should be related over the business cycle, and the nature of the relationship should convey information about the sources of shocks. (Demand shocks produce positive price-quantity correlation and supply shocks produce negative price-quantity correlation.) Hence we now proceed to examine real activity and inflation together over the cycle. 
We plot our real activity and inflation indexes in the top panel of Figure 5, together with NBER recession bars. We plot real activity on the left scale (thick font) and inflation on the right (thin font), so that movements in the two series do not obscure one another. Movements in real activity and inflation cohere over the business cycle, and crucially, the nature of the coherence does indeed depend on whether recessions are demand- or supply-driven. The inflation index tends to drop in most recessions, consistent with adverse demand shocks, as for example in the "Volcker recession" of the early 1980s. In contrast, the mid-1970s and 1980 oil shock recessions show decreased real activity and increased inflation, consistent with adverse supply shocks.

In the bottom panel of Figure 5 we zoom in on the recent recession. Inflation falls both more sharply and later than real activity, plunging only in summer 2008, whereas real activity begins its descent in 2007. Inflation also recovers both more sharply and sooner than real activity, returning to baseline within approximately six months.

If differing descent and rebound patterns in real activity and inflation during the recent recession are interesting, the similarities are also striking and ultimately more important. The bottom panel of Figure 5 clearly shows strong positive co-movement of real activity and inflation during the recent recession, consistent with an adverse demand shock.

\section{Summary and Concluding Remarks}

We have used a dynamic-factor approach to extract indexes of U.S. real activity and inflation. Key aspects of our approach are its use of high-frequency data, its natural implementation in a state-space environment via Kalman filtering, and its related natural facilitating of real-time updating as data are released.

Historically, our real activity index closely matches the NBER chronology and captures widely-discussed phenomena such as the "Great Moderation". Our inflation index also follows the cycle, with the sign of the correlation varying, depending on whether various recessions are supply- or demand-driven.

The recent recession is of central interest, not least because of its severity. In terms of real activity, our results indicate that it was the most severe since 1960. Interestingly, however, its depth does not appear to be the most severe since 1960, as the the mid-1970s and 1980 recessions were a bit deeper. Instead, the most unusual aspect of the recent

recession's real activity movement is its duration. This extreme duration severity interacts with the moderately extreme depth severity to produce very extreme overall severity. A 
second extreme movement during the recent recession concerns inflation as opposed to real activity, as the the 2008 collapse of inflation pressure appears to be the most pronounced on record since 1960, by far. Finally, real activity and inflation appear strongly positively correlated during the recent recession, consistent with a "traditional" Keynesian demandbased explanation. Indeed the recent recession, although the most severe during the last fifty years - as by definition one or another must be - is similar in its essentials to most others. Hence we are wary of assertions that "this time is different" not only with regard to financial market booms (as emphasized by Reinhart and Rogoff (2009)), but also with regard to business cycle busts.

The work begun here can be extended in several potentially fruitful directions. In work in progress, for example, we assess the possible presence of regime-switching in extracted factors, as in Diebold and Rudebusch (1996), both from the highbrow perspective of incorporating nonlinear aspects of the cycle, and from the pragmatic perspective of transforming our indexes in ways that may enhance their interpretability. In addition we are extending our framework to the global environment, estimating a hierarchical global dynamic factor model in the tradition of Kose et al. (2003), with country indicators depending on country factors, country factors potentially depending on regional factors, and regional factors potentially depending on global factors. 


\section{References}

Altissimo, F., R. Cristadoro, M. Forni, M. Lippi, and G. Veronese (2007), "New EuroCOIN: Tracking Economic Growth in Real Time," CEPR Discussion Paper No. 5633.

Aruoba, S.B. and F.X. Diebold (2009), "Updates on ADS Index Calculation," Manuscript, www.philadelphiafed.org/research-and-data/real-time-center/business-conditions-index/.

Aruoba, S.B., F.X. Diebold, and C. Scotti (2009), "Real Time Measurement of Business Conditions," Journal of Business and Economic Statistics, 27, 417-427.

Bai, J. and S. Ng (2008), "Forecasting Economic Time Series Using Targeted Predictors," Journal of Econometrics, 146, 304-317.

Camacho, M. and G. Perez-Quiros (2009), "Introducing the Euro-STING: Short Term INdicator of Euro Area Growth," Journal of Applied Econometrics, in press.

Choi, H. and H. Varian (2009), "Predicting the Present with Google Trends," Unpublished Manuscript, Google Inc., www.googleresearch.blogspot.com.

Croushore, D. (2006), "Forecasting with Real-Time Macroeconomic Data," in "Handbook of Economic Forecasting," (edited by Elliot, G., C.W.J. Granger, and A. Timmermann), 961-1012, Amsterdam: North-Holland.

Diebold, F.X. (2003), "Big Data Dynamic Factor Models for Macroeconomic Measurement and Forecasting," in "Advances in Economics and Econometrics: Theory and Applications, Eighth World Congress of the Econometric Society," (edited by M. Dewatripont, L.P. Hansen and S. Turnovsky), 115-122, Cambridge University Press.

Diebold, F.X. and G.D. Rudebusch (1992), "Have Postwar Economic Fluctuations Been Stabilized?" American Economic Review, 82, 993-1005.

Diebold, F.X. and G.D. Rudebusch (1996), "Measuring Business Cycles: A Modern Perspective," Review of Economics and Statistics, 78, 67-77.

Doz, C., D. Giannone, and L. Reichlin (2006), "A Quasi Maximum Likelihood Approach for Large Dynamic-Factor Models," CEPR Working Paper.

Durbin, J. and S.J. Koopman (2001), Time Series Analysis by State Space Methods, Oxford: Oxford University Press. 
Harvey, A.C. (1991), Forecasting, Structural Time Series Models and the Kalman Filter, Cambridge: Cambridge University Press.

Jungbacker, B. and S.J. Koopman (2008), "Likelihood-based Analysis for Dynamic Factor Models," Tinbergen Institute Working Paper 2008-0007-4.

Kose, M.A., C. Otrok, and C.H. Whiteman (2003), "International Business Cycles: World, Region, and Country-Specific Factors," The American Economic Review, 93, 1216-1239.

Levin, A.T., A. Onatski, J. Williams, and N.M. Williams (2006), "Monetary Policy Under Uncertainty in Micro-Founded Macroeconometric Models," in "NBER Macroeconomics Annual 2005 (Volume 20)," 229-312, National Bureau of Economic Research, Inc.

Mariano, R.S. and Y. Murasawa (2003), "A New Coincident Index of Business Cycles Based on Monthly and Quarterly Series," Journal of Applied Econometrics, 18, 427-443.

Reinhart, C. and K. Rogoff (2009), This Time is Different: Eight Centuries of Financial Folly, Princeton: Princeton University Press.

Reis, R. and M.W. Watson (2009), "Relative Goods' Prices, Pure Inflation, and the Phillips Correlation," American Economic Journal: Macroeconomics, in press.

Schmitt-Grohe, S. and M. Uribe (2007), "Optimal Inflation Stabilization in a MediumScale Macroeconomic Model," in "Monetary Policy Under Inflation Targeting," (edited by Schmidt-Hebbel, K. and F. Mishkin), 125-186, Central Bank of Chile.

Stock, J.H. and M.W. Watson (1989), "New Indexes of Coincident and Leading Economic Indicators," NBER Macroeconomics Annual, 4, 351-394.

Stock, J.H. and M.W. Watson (2007), "Why Has U.S. Inflation Become Harder to Forecast?" Journal of Money, Credit and Banking, 39, 3-34.

Taylor, J.B. (2009), " Empirically Evaluating Economic Policy in Real Time," First Annual Martin Feldstein Lecture, Delivered to the National Bureau of Economic Research, Cambridge, Mass., June 10. 
Figure 1: Real Activity Indicators and Extracted Real Activity Index

Five Real Activity Indicators
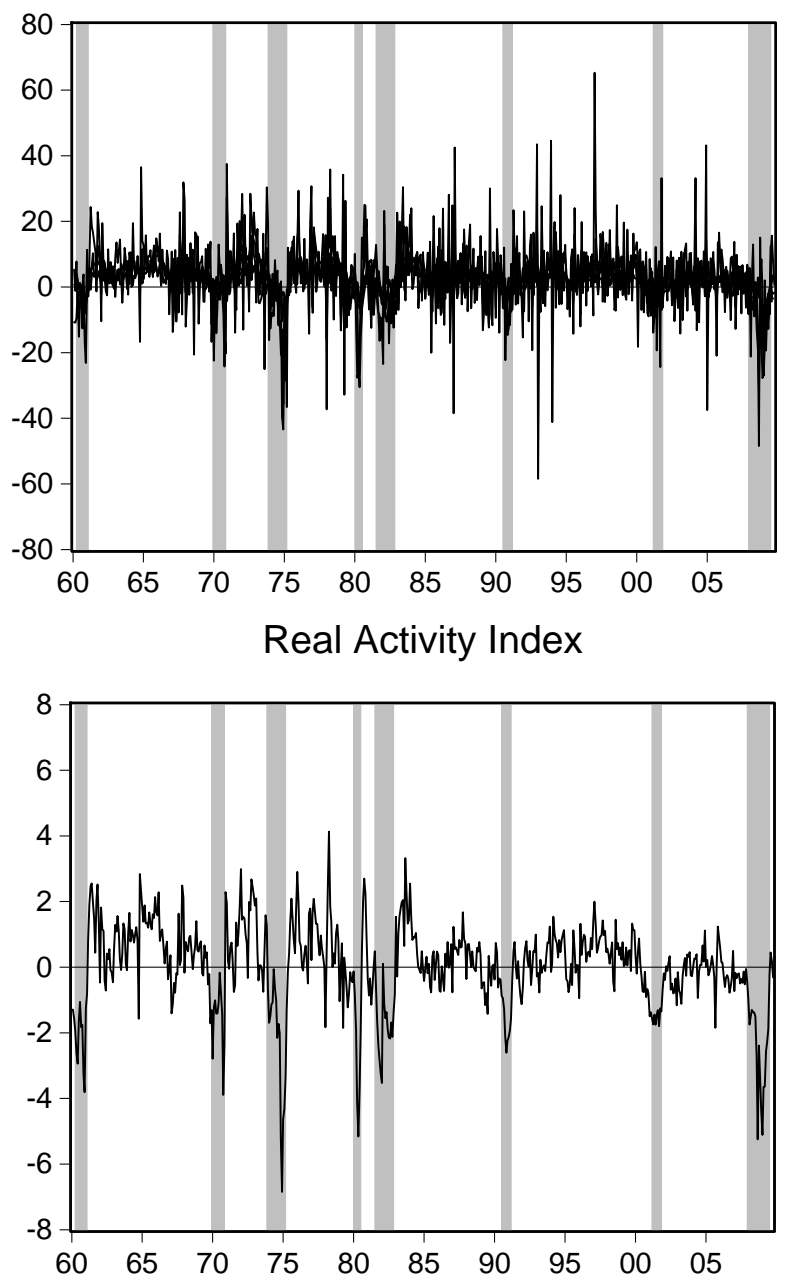

Real Activity Index, 2007-2009

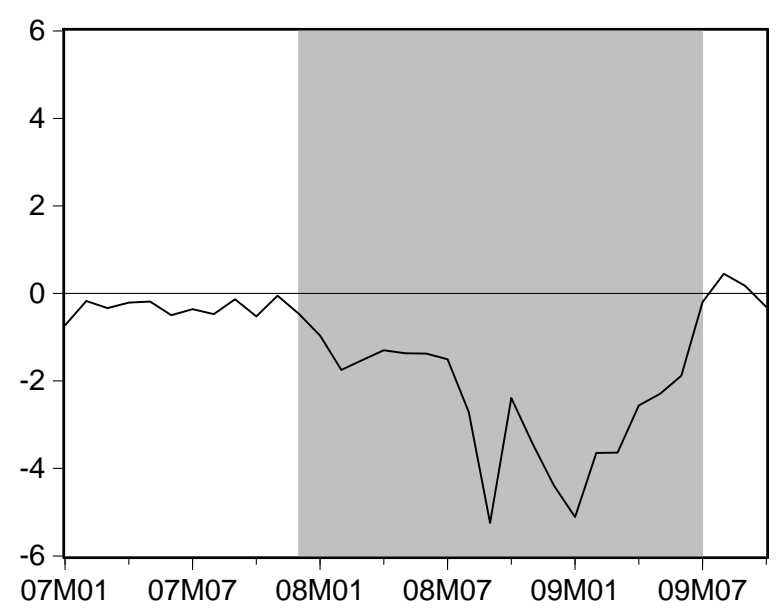


Figure 2: Real Activity Index During Recessions

1973-1975 Recession

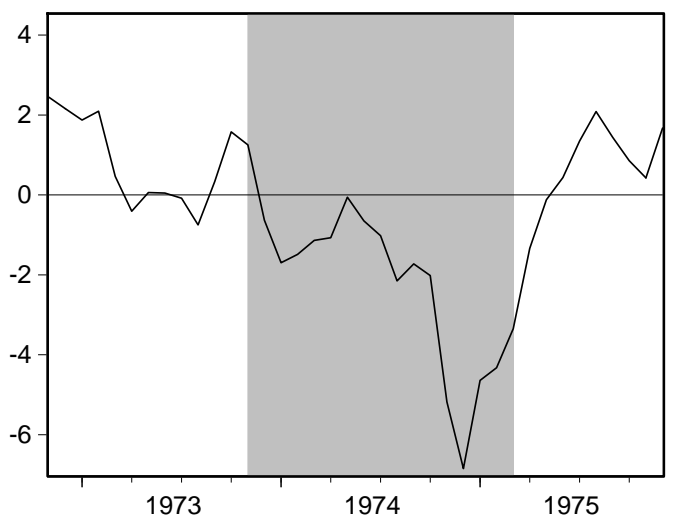

1981-1982 Recession

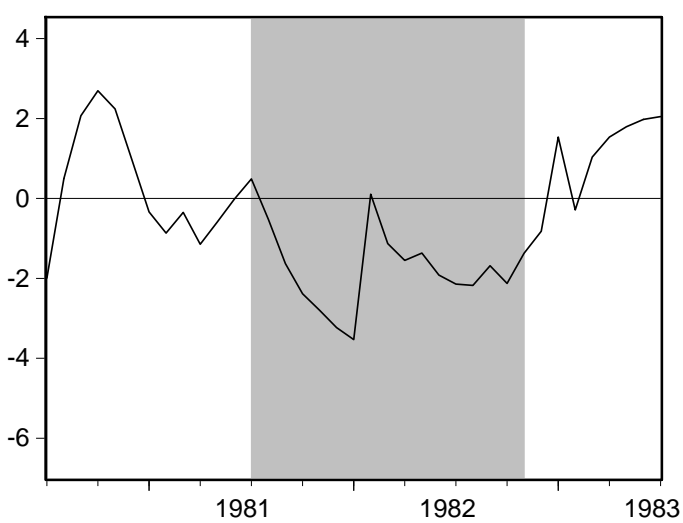

2001 Recession

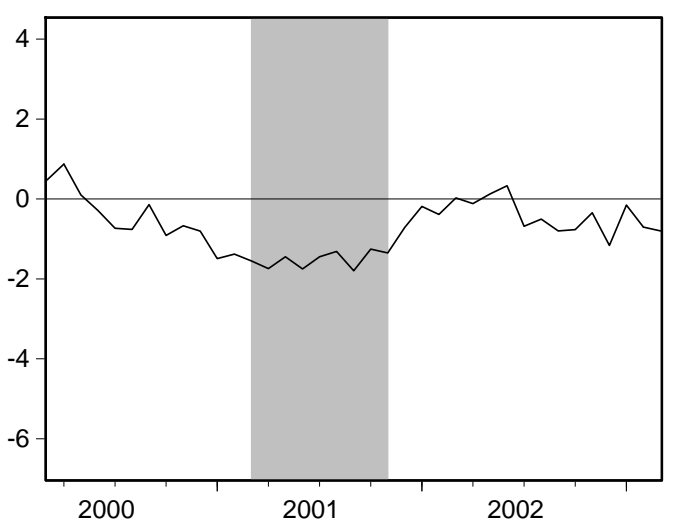

1980 Recession

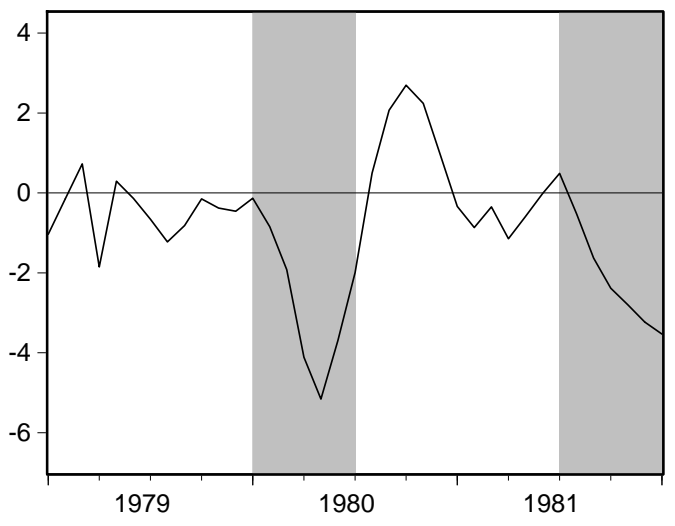

1990-1991 Recession

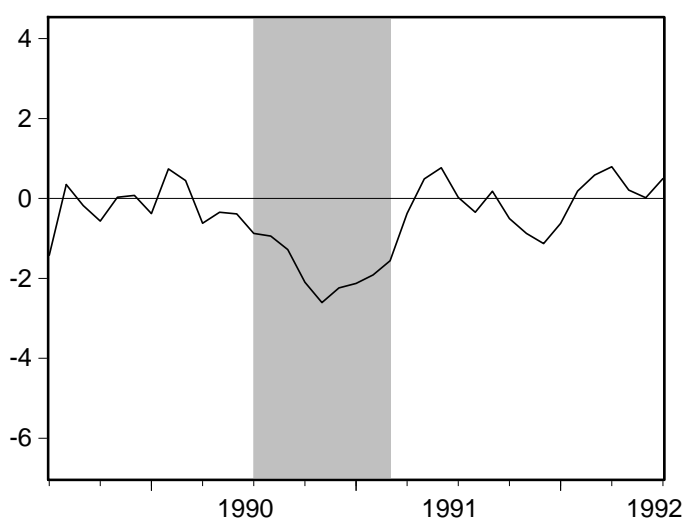

2007-2009 Recession

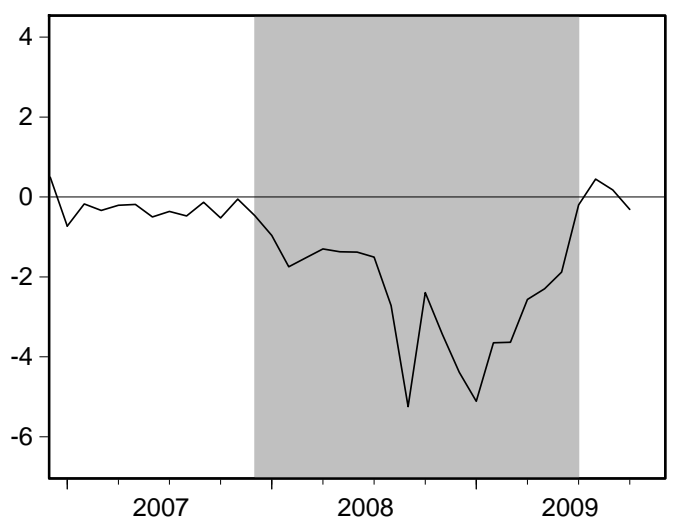


Figure 3: Recession Severities: Depth, Duration and Overall

Recession Depth Severity

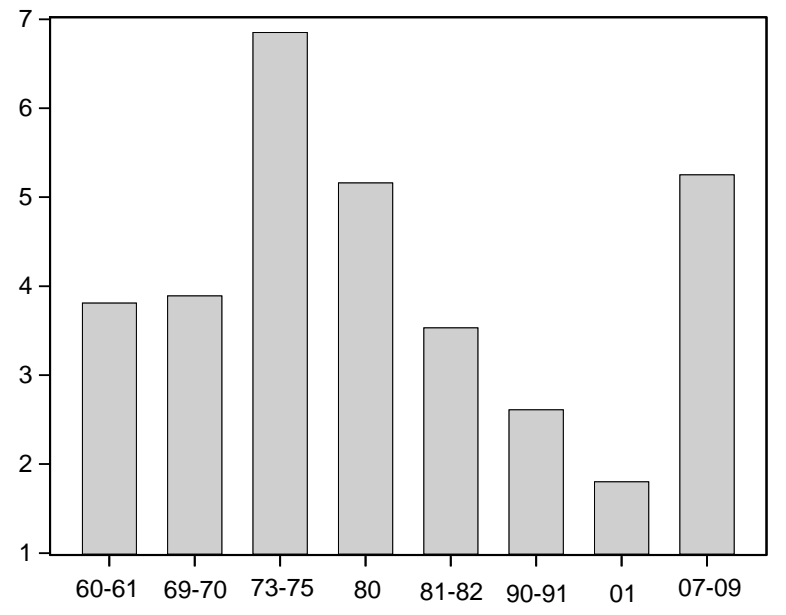

Recession Duration Severity

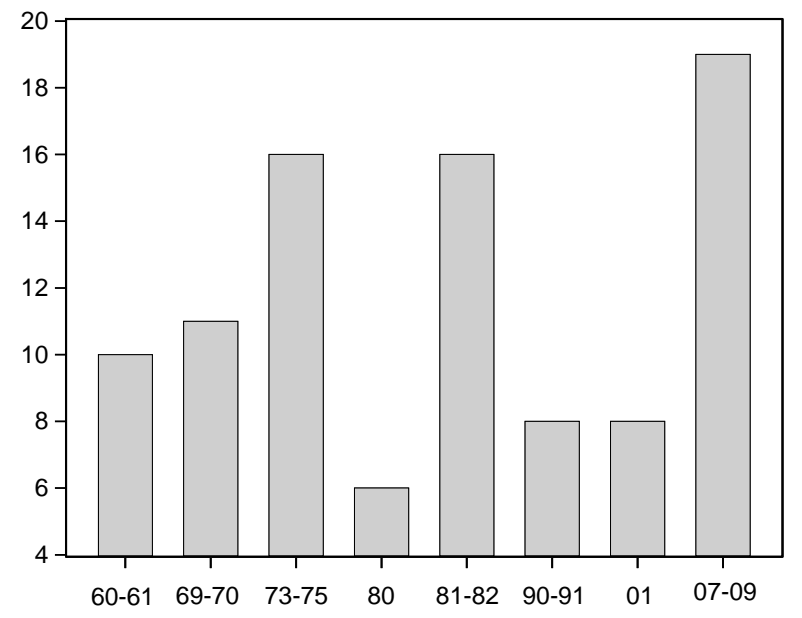

Overall Recession Severity

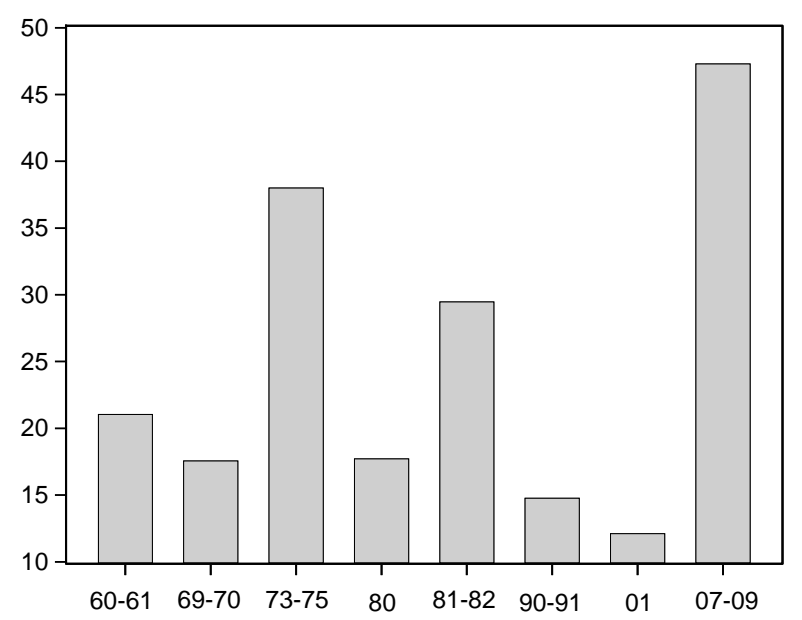


Figure 4: Inflation Activity Indicators and Extracted Inflation Index Six Inflation Indicators
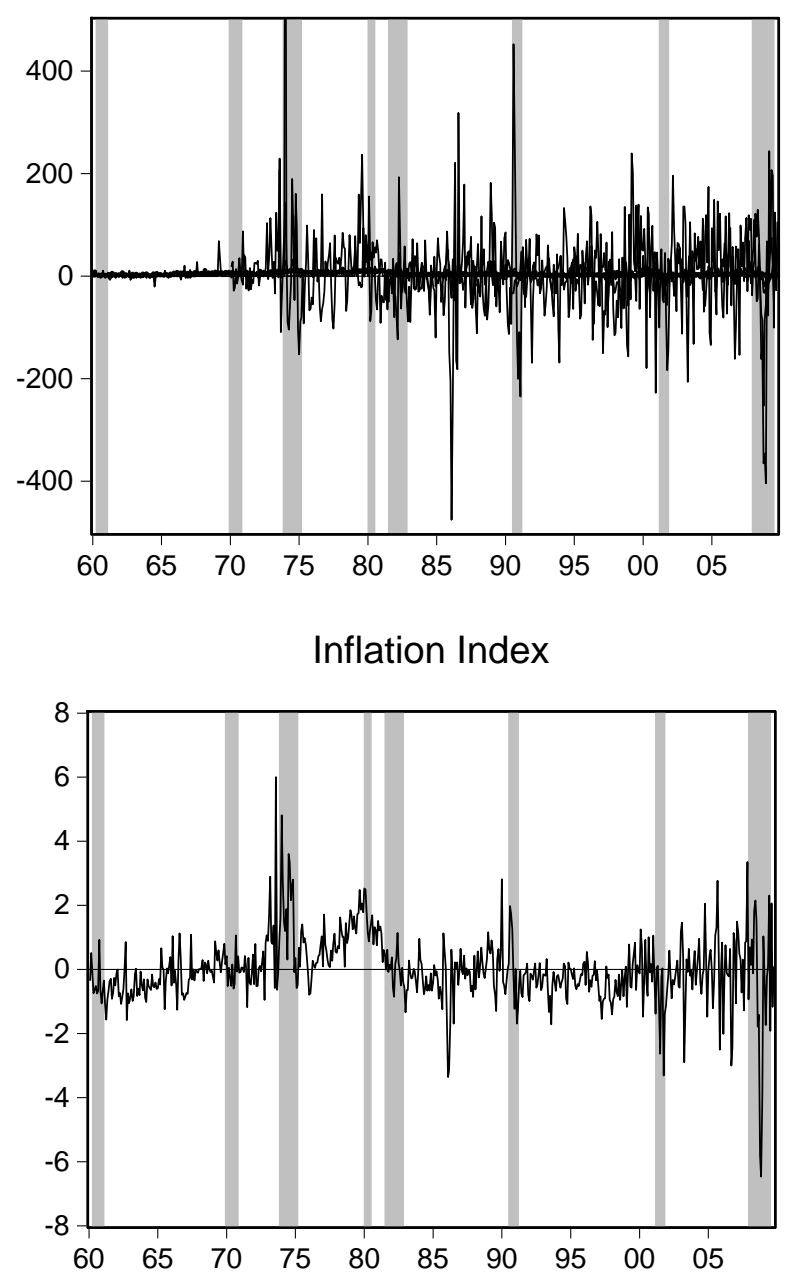

Inflation Index, 2007-2009

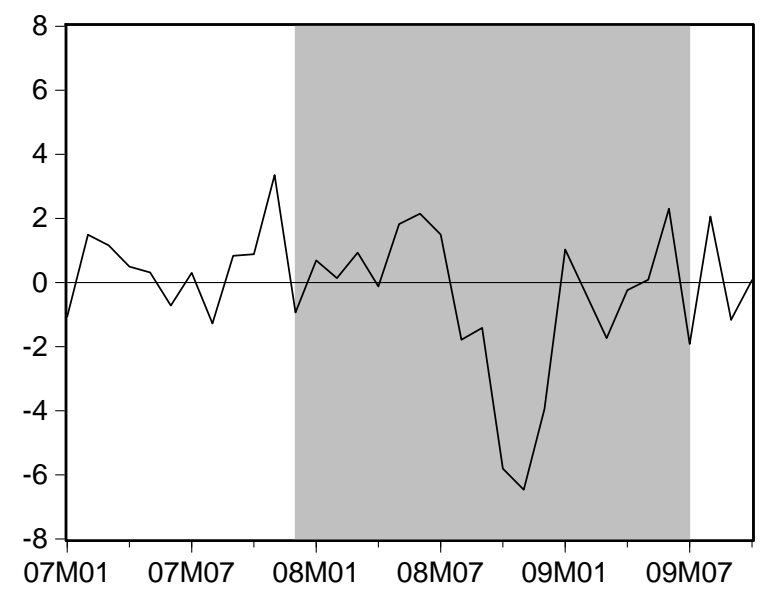


Figure 5: Real Activity and Inflation Over the Cycle

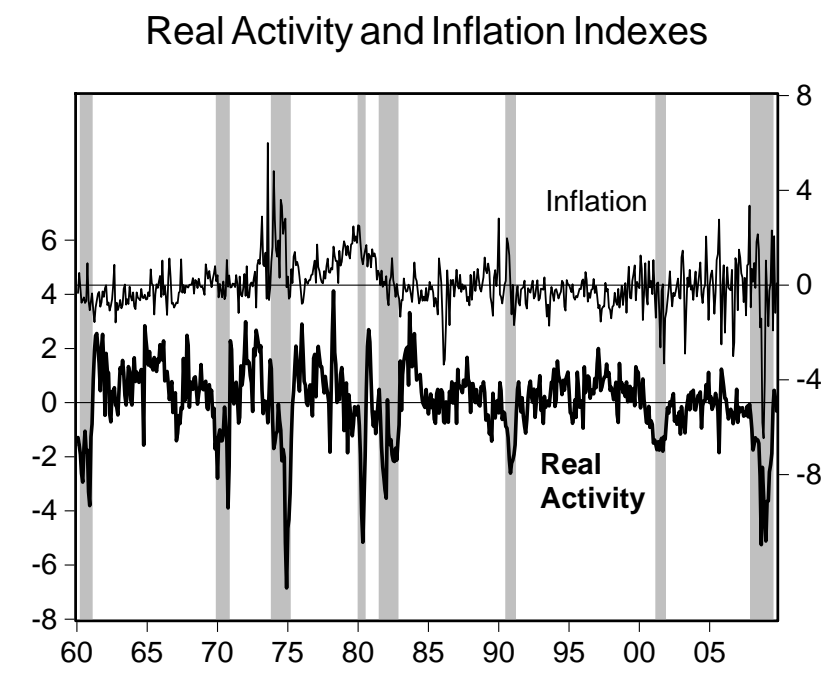

Real Activity and Inflation Indexes, 2007-2009

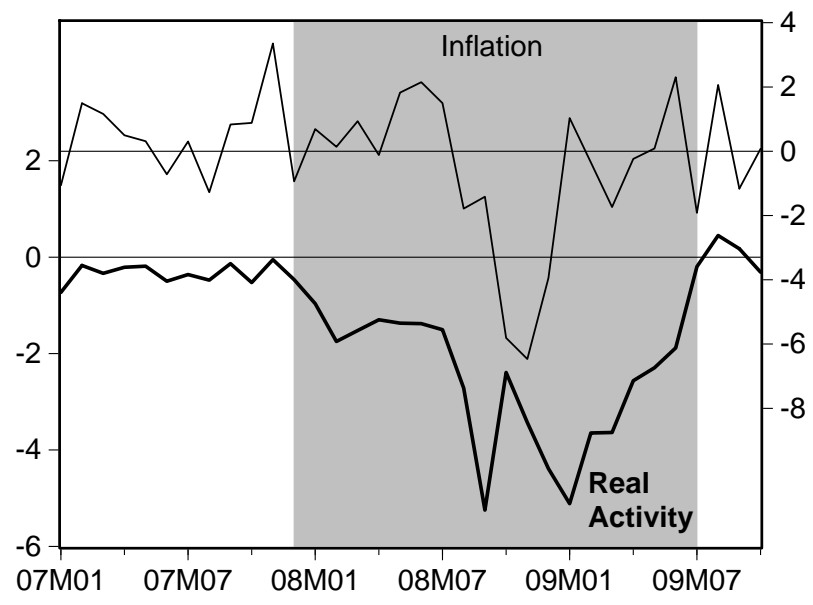

